\title{
Spiral Artery of the Endometrium
}

National Cancer Institute

\section{Source}

National Cancer Institute. Spiral Artery of the Endometrium. NCI Thesaurus. Code C33592.

An artery that originates from the radial artery and supplies the functional zone of the endometrium. 